

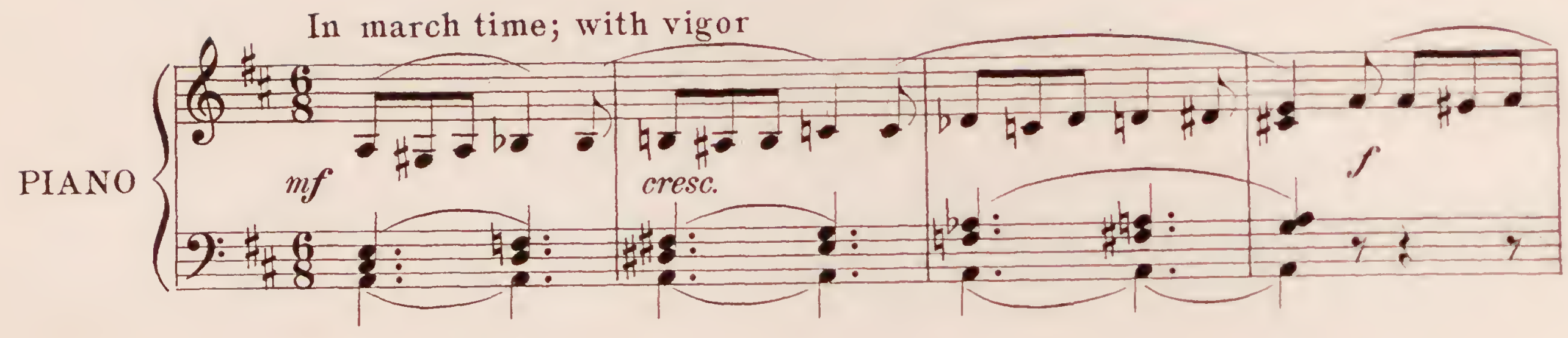
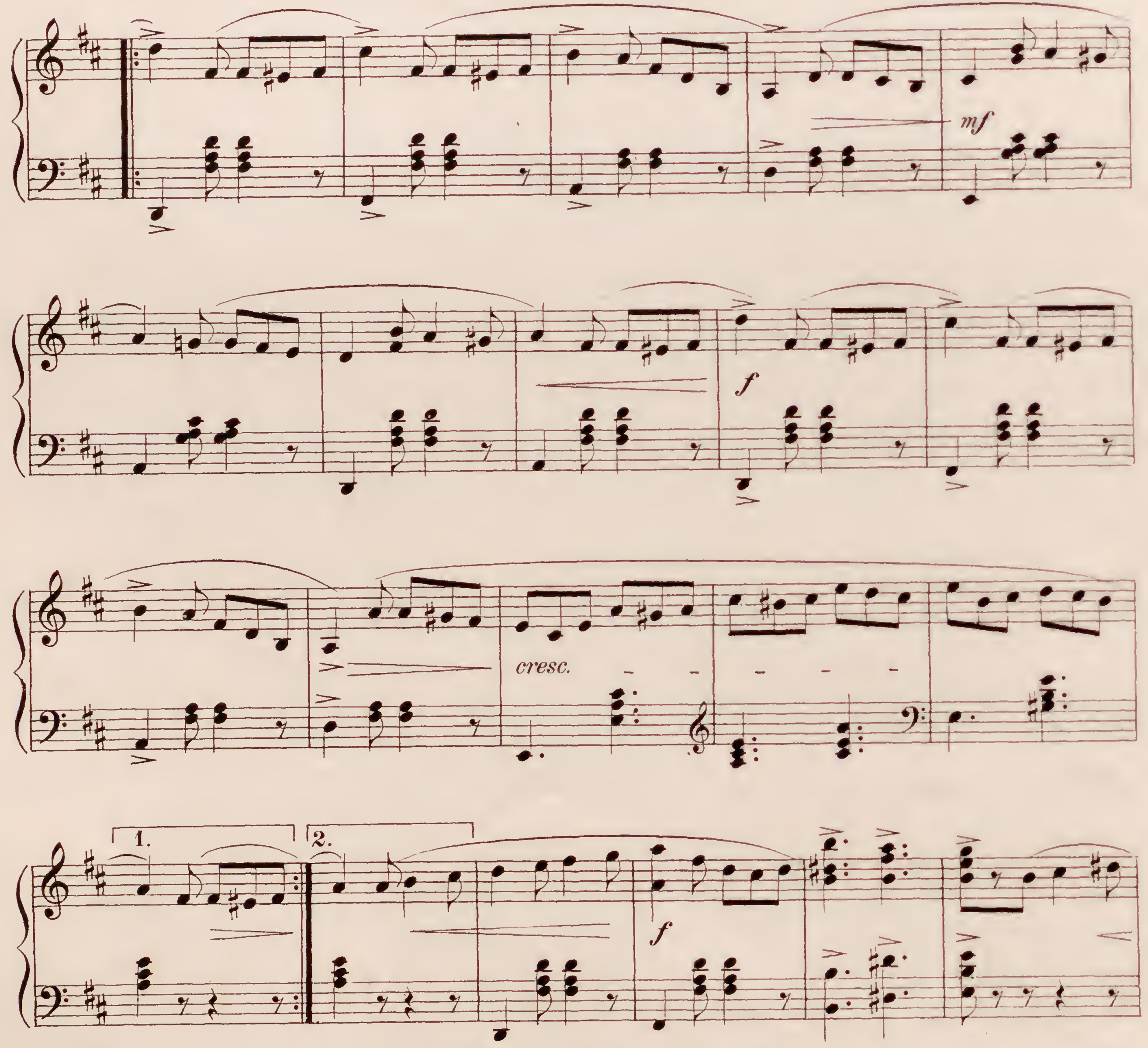


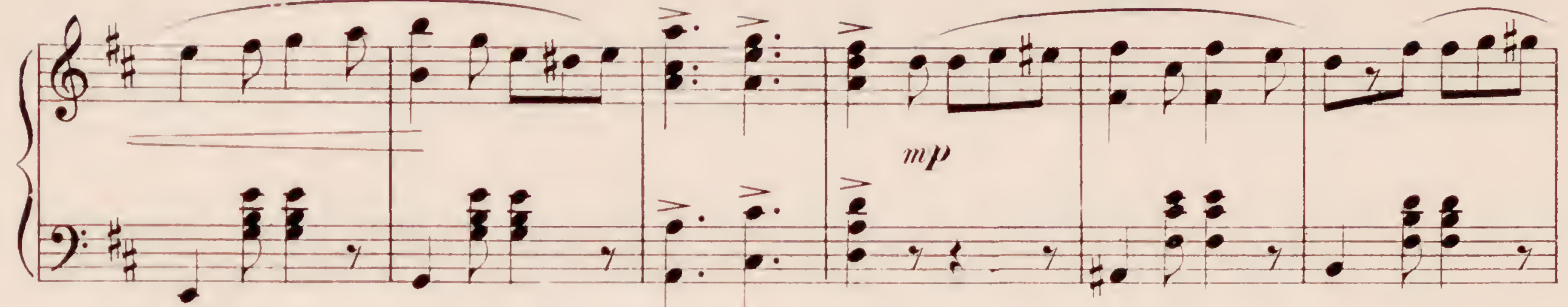

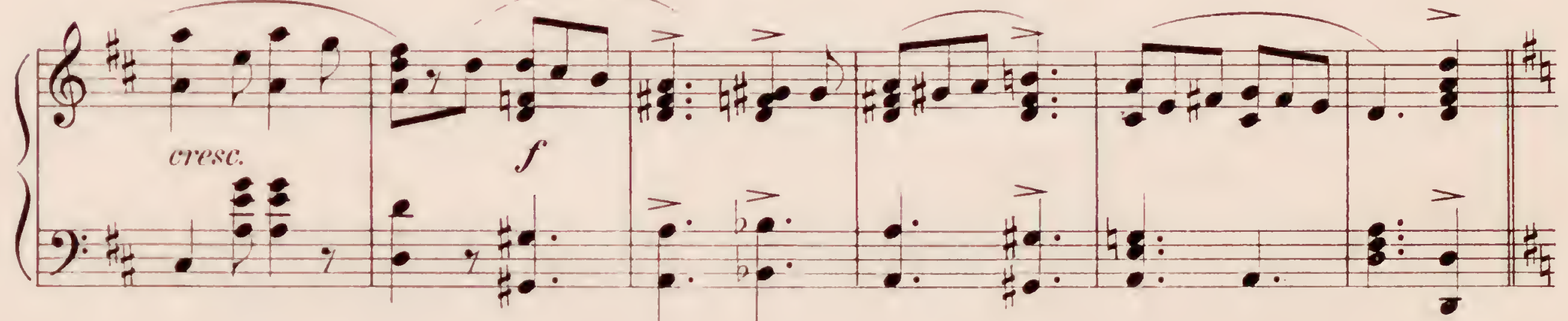

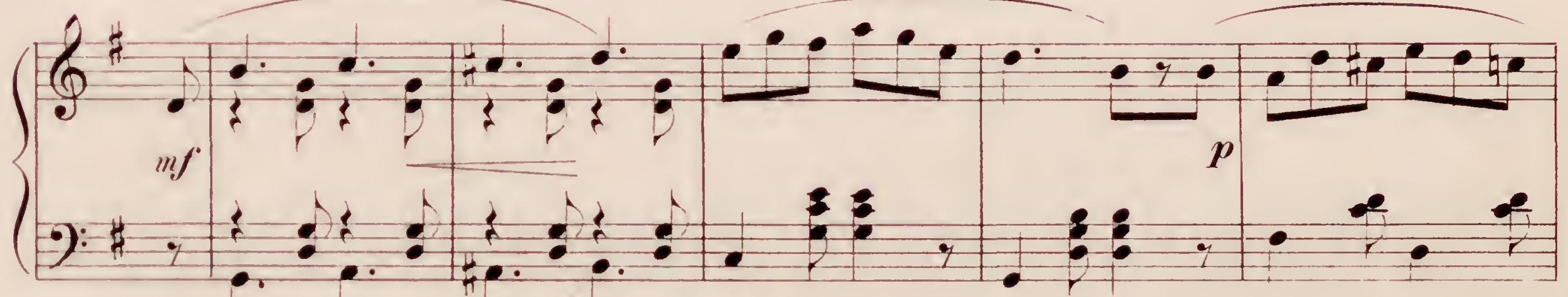

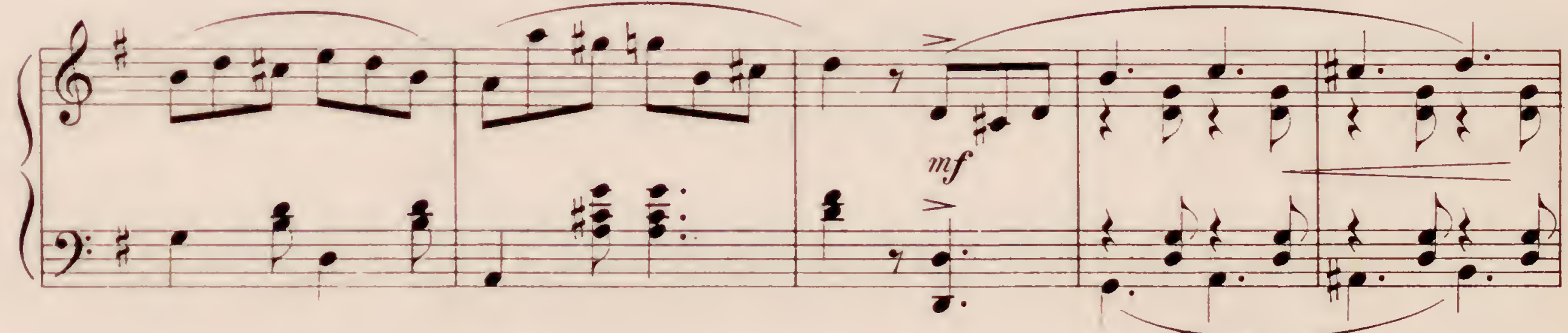

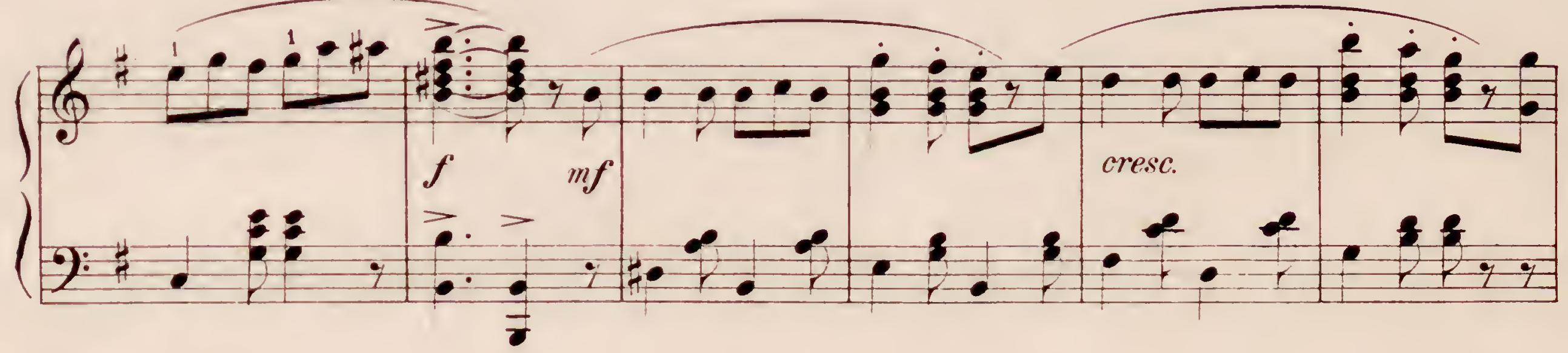



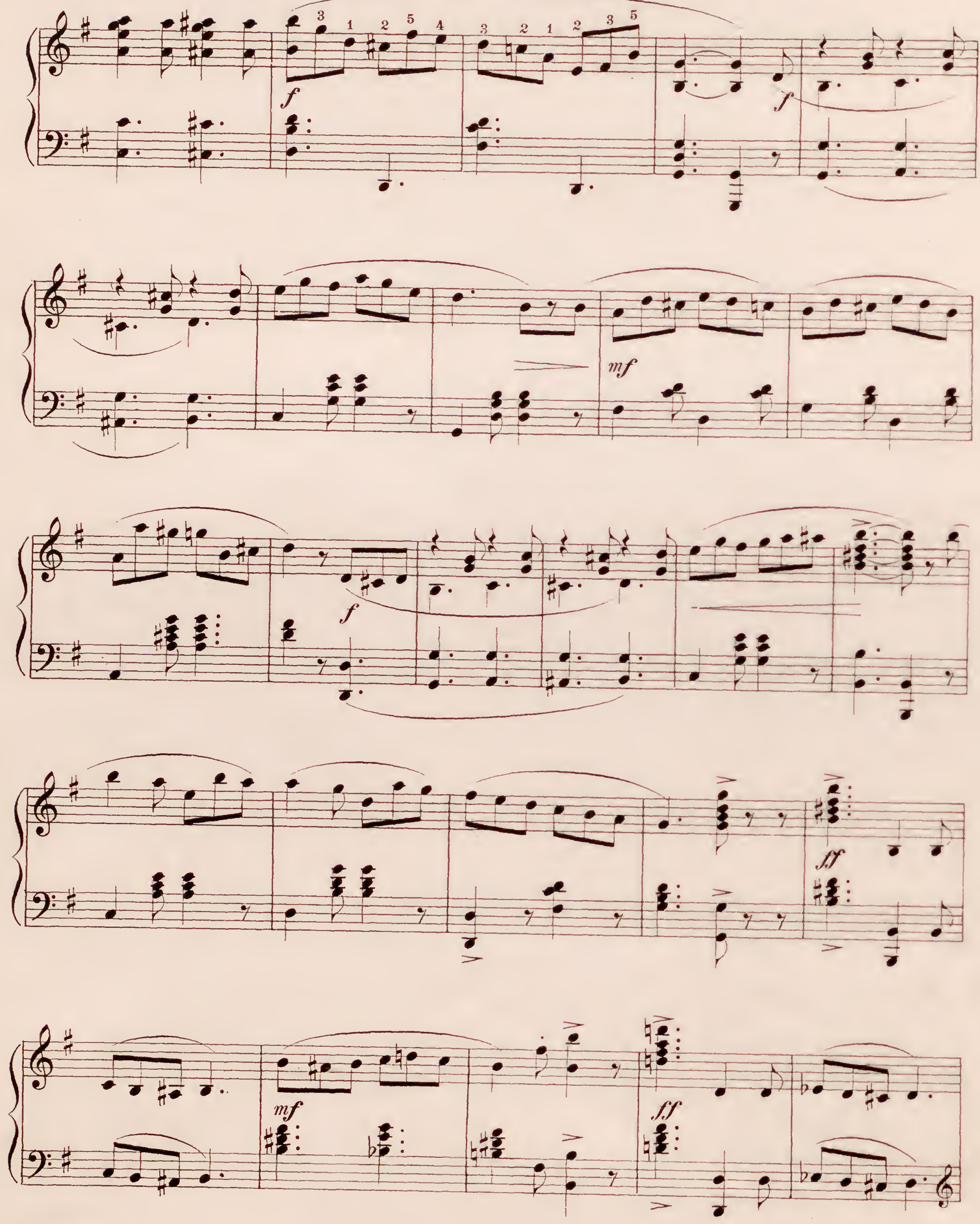


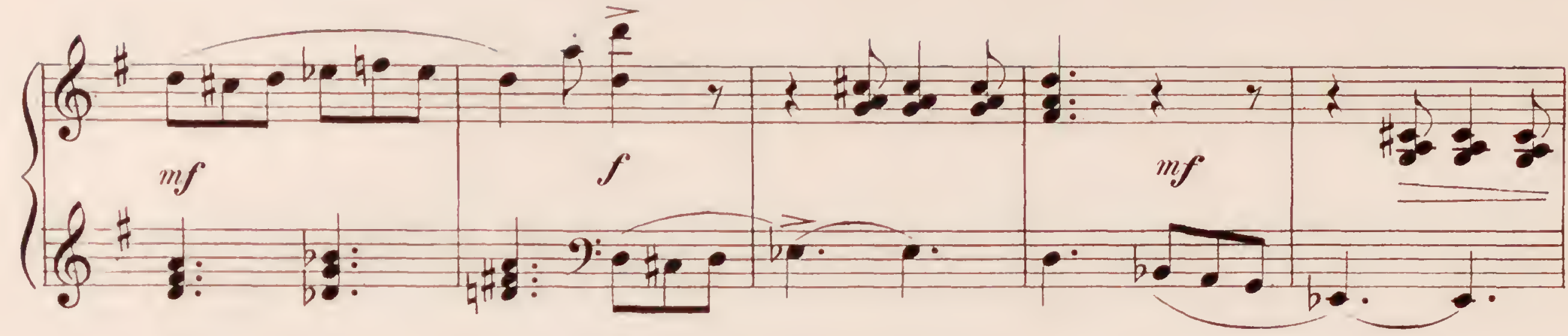

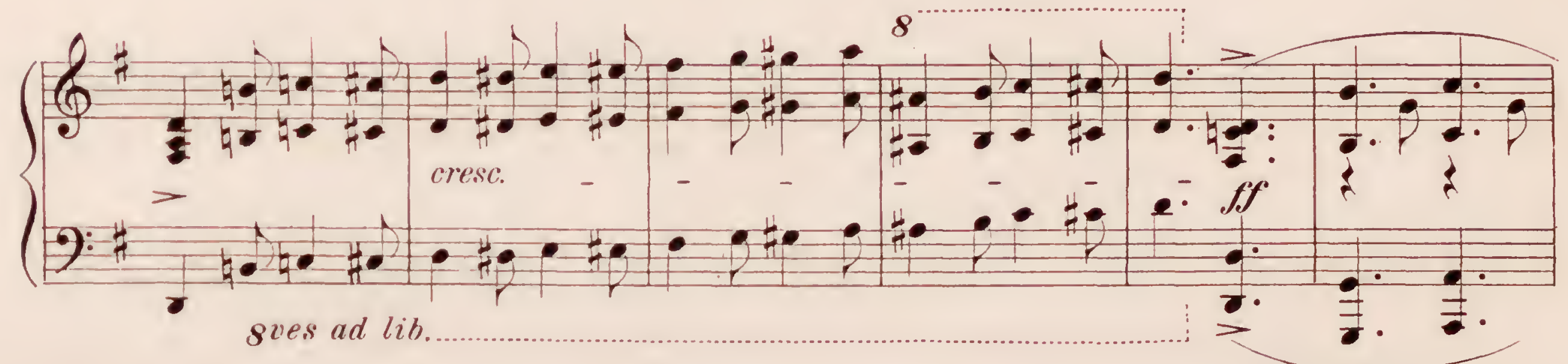
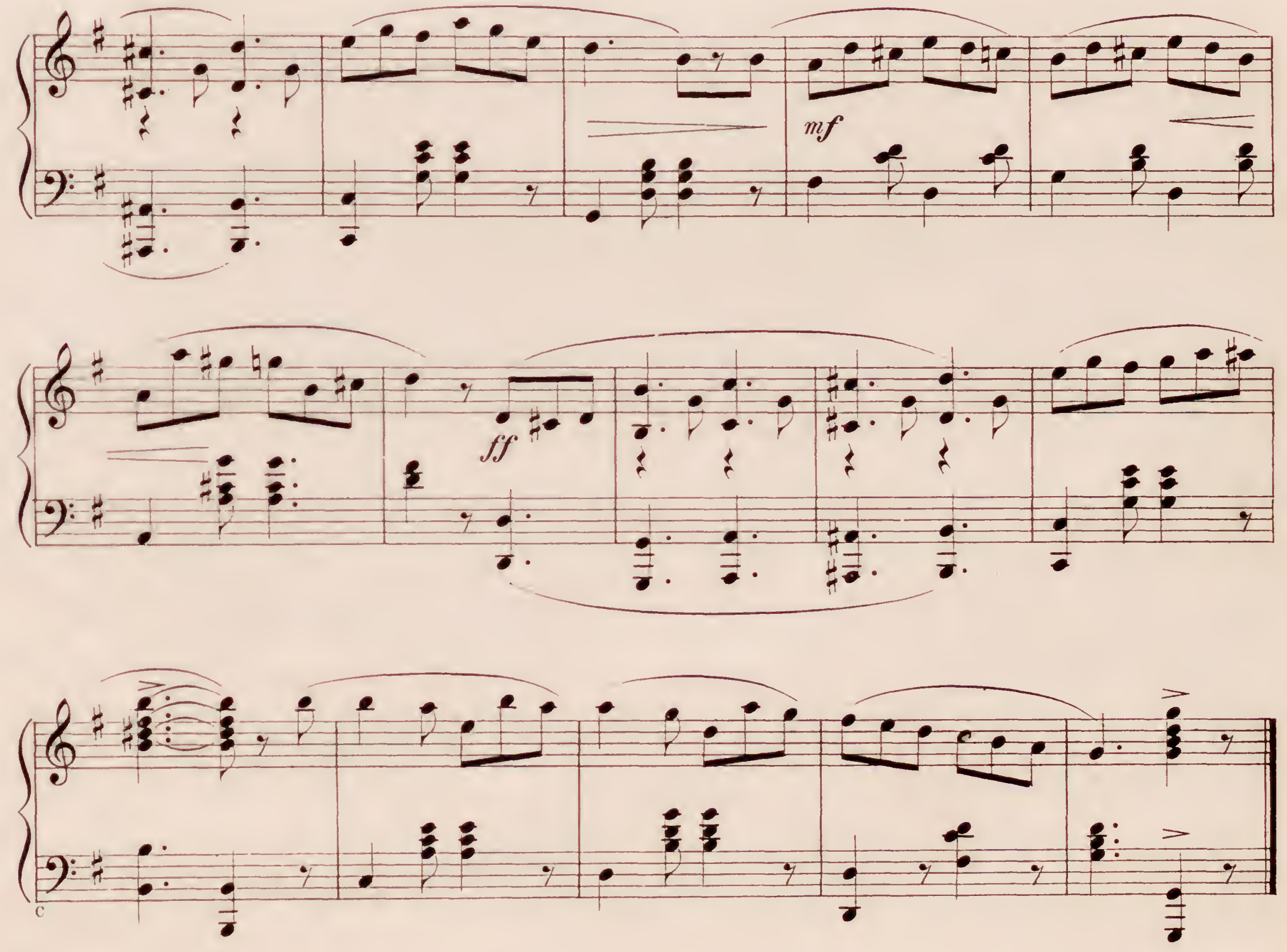


\section{SHADOW DANCE}

INTRODUCTION

Allegro con spirito

H, KNGELMANN, Op. 740

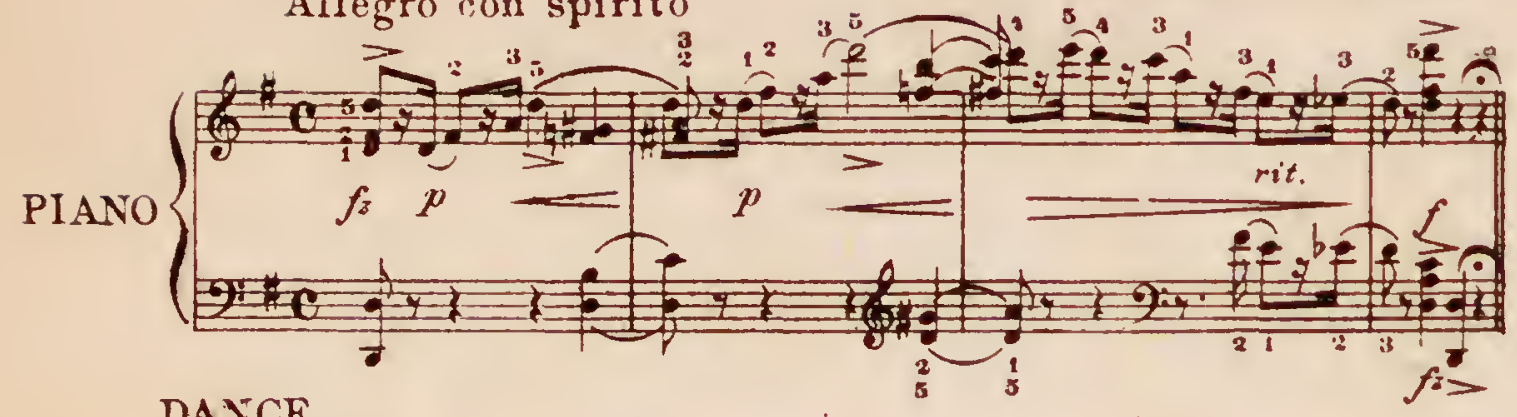

DANCE

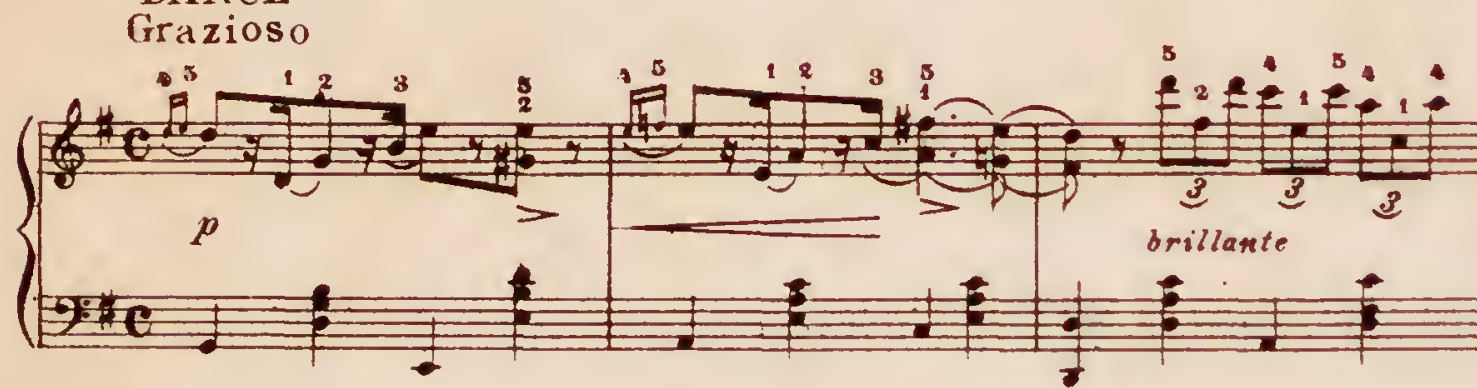
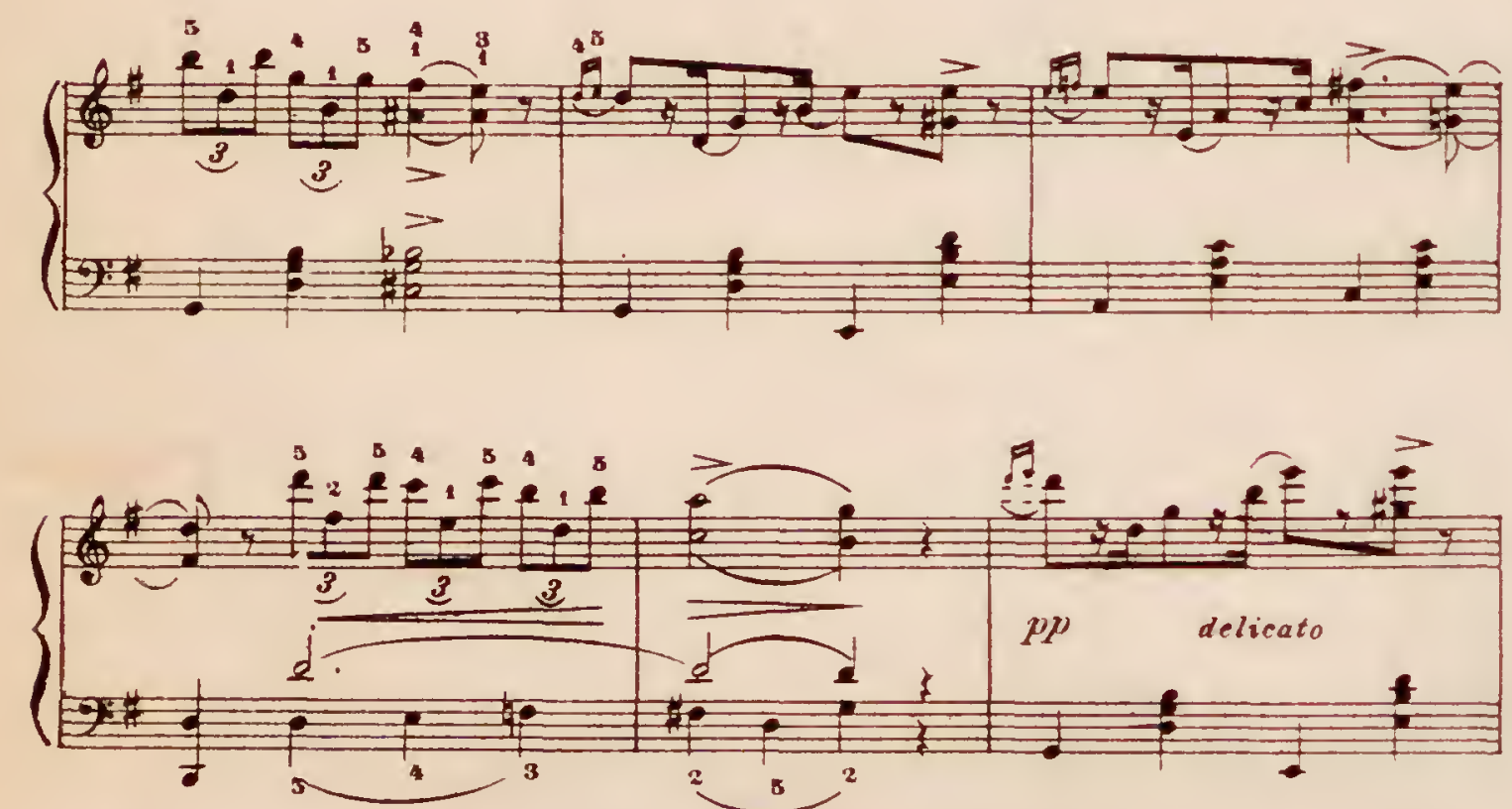

Grade IIT-Tr Copyright MCMV by oliver Diteon Company International Copyright Secured

Price 60\%

VANISHED DREAMS

(VALSE DE SALON)
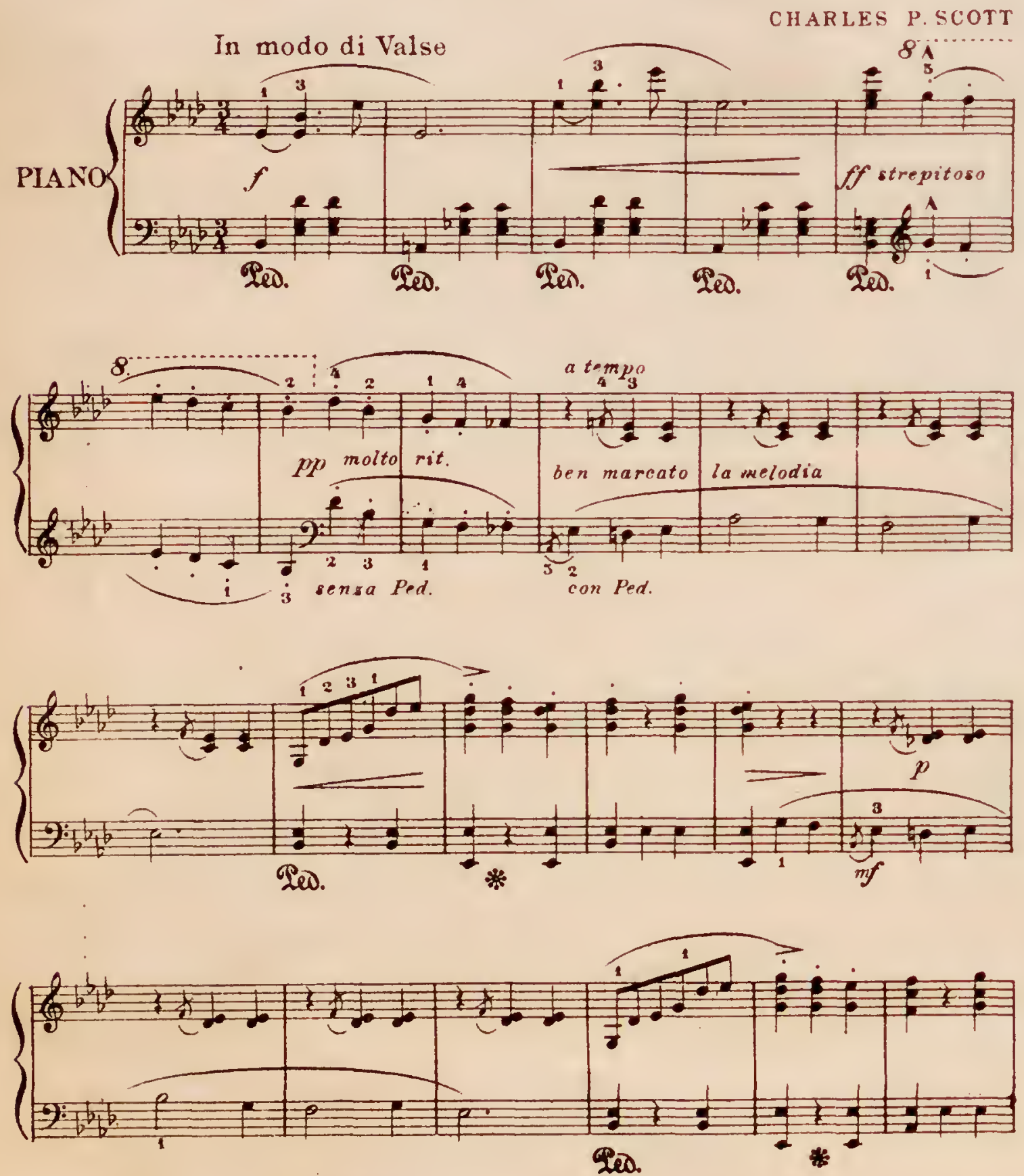

คeo.
IUST FOR THE FUN OF IT

(RONDO CAPRICE)

Allegro moderato scherzando W. F. Stents, op, 30u

PIANO

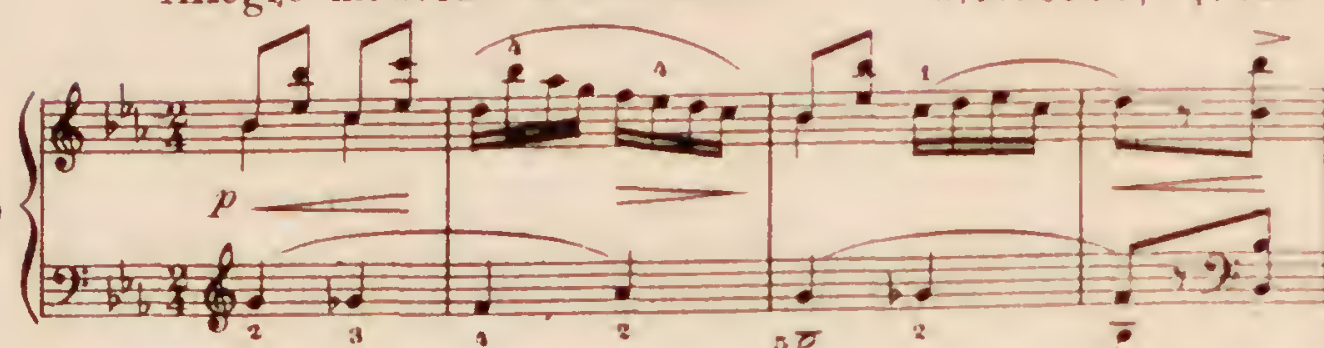

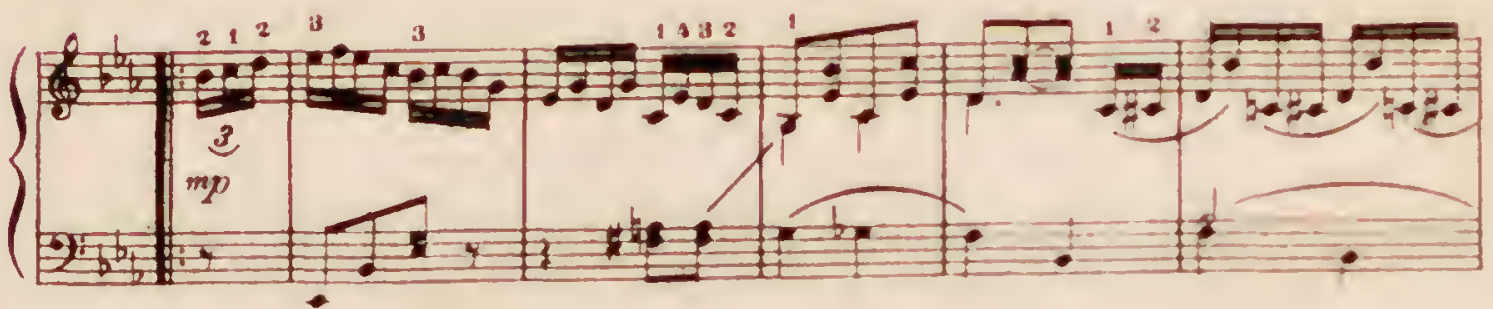
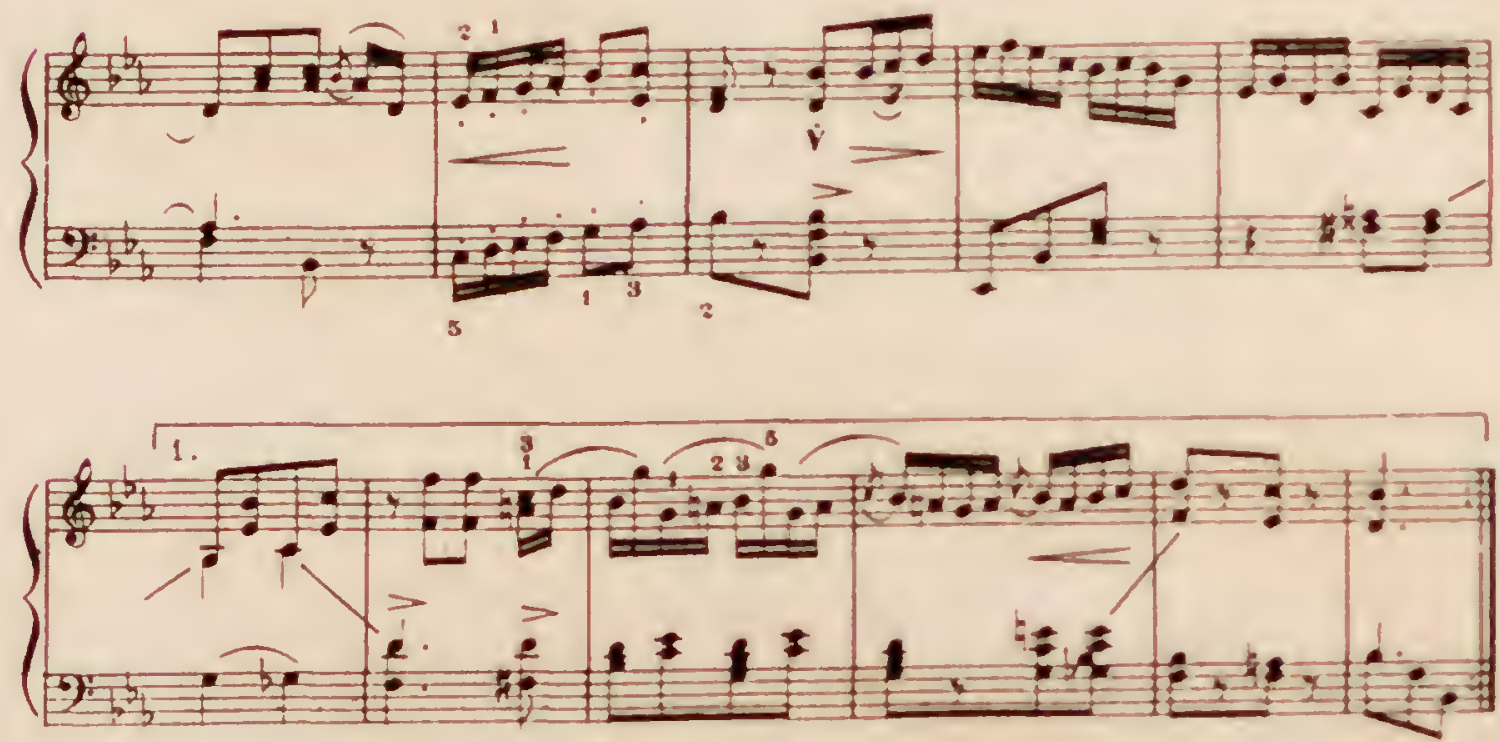

Grade III

Copyrighe MCIris by Oliver Ditoen Company Internatonal copyrakt secured

Price cor

\section{TWILIGHT THOUGHTS}

(REVERIE)

CHARIES WAKFFIFID CAUMAS

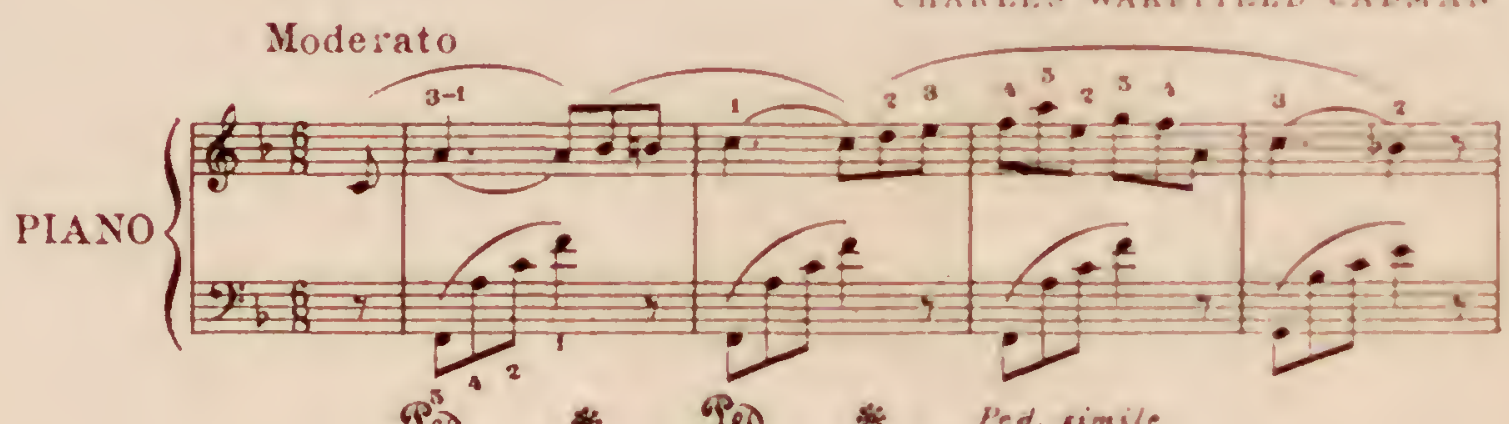
Led * Ded. * Ped. cimile
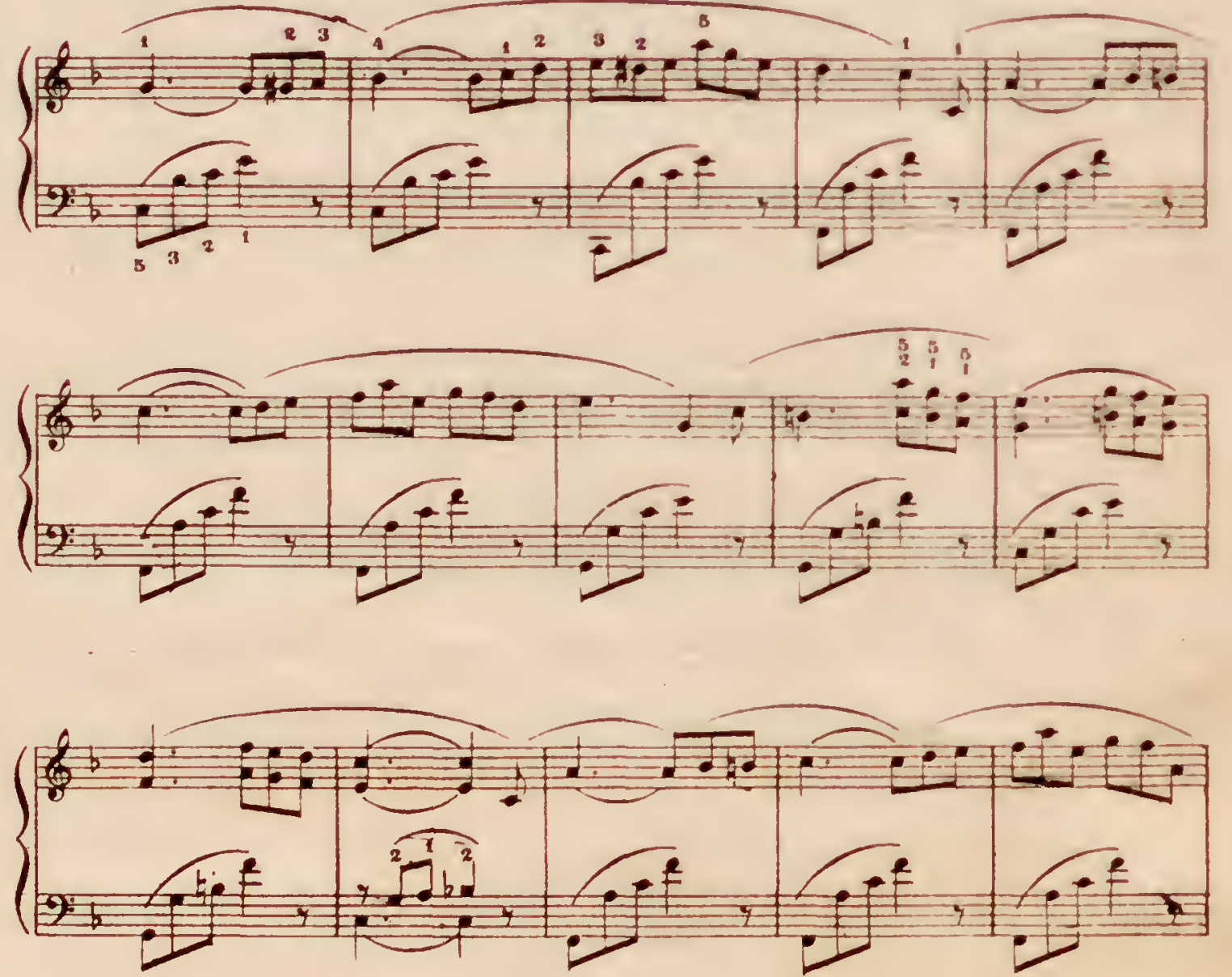

Grade III Copyright. MCMV by Oliver Ditson Company

Price $60 \%$ 